\title{
Documentação da RSP
}

1. Legislação Básica

\section{1 - DECRETO-LEI N. ${ }^{\circ} 1.870$ - DE 14 DE DEZEMBRO DE 1939 .}

Reconhece a Revista do Serviço Público como órgão de interesse da Administração e dá outras providências.

O Presidente da República, usando da atribuição que the confere 0 art. 180 da Constituição, decreta :

Art. $1 .^{\circ}$ A Revista do Serviço Público, editada pelo Departamento Administrativo do Serviço Público, fica reconhecida como órgão de interesse da Administração.

Parágrafo único. A sede da Revista será a do Departamento Administrativo do Serviço Público.

Art. 2. ${ }^{\circ}$ A Revista terá um diretor, designado pelo Presidente do DASP dentre o corpo de redatores, constituído por funcionários requisitados e extranumerários admitidos na forma da legislação em vigor.

Art. $33^{\circ}$ A orientação da Revista competirá ao Presidente do DASP e a direção técnica e administrativa ao seu diretor, sob o controle econômico e financeiro do Chefe dos Serviços Auxiliares.
Art. $4 .^{\circ} \mathrm{O}$ Presidente do DASP fica autorizado a regular as atividades da Revista, em Regimento Interno, ouvido o Conselho Deliberativo.

Art. 5..$^{\circ}$ As despesas com a edição da Revista, inclusive as de colaboração e de material, e bem assim as decorrentes da publicação de quaisquer trabalhos avulsos que visem o aperfeiçoamento do serviço público, correrão à conta das dotações para isso consignadas no orçamento $d a$ União.

Parágrafo único. Essas dotações serão requisitadas pelo Chefe dos Serviços Auxiliares, em quotas trimestrais adiantadas, cuja aplicação comprovará, na forma da legislação em vigor.

Art. 6. ${ }^{\circ}$ A renda da Revista, constante do produto de assinaturas e da venda avulsa, deduzidas as importâncias das comissões pagas, será recoIhida mensalmente ao Tesouro, como receita da União.

Art. 7..$^{\circ}$ A escrituração da Revista será feita por funcionário ou extranumerário, designado pelo Presidente do DASP, de acordo com as instruções aprovadas pela Contadoria Central da República.

$\S 10^{\circ}$ Até o dia 31 de janeiro, o Chefe dos Serviços Auxiliares subme- 
terá ao Presidente do DASP o balanço da receita e despesa da Revista e $\circ$ balanço final correspondentes ao ano anterior.

§ 2..$^{\circ}$ Uma cópia desse balanço será remetida à Contadoria Central da República.

Art. $8 .^{\circ}$ Parte da tiragem da Revista será distribuída gratuitamente, conforme determinar o Presidente do DASP.

Art. 9. ${ }^{\circ}$ O presente decreto-lei entrará em vigor na data de sua publicação, menos quanto ao regime finan. ceiro, que começará a ter execução no exercício de 1940.

Art. 10 Revogam-se as disposiçöes em contrário.

Rio de Janeiro, 14 de dezembro de $1939,118 .^{\circ}$ da Independência e $51 .^{\circ}$ da República.

\section{GETÚLIO VARGAS}

\section{Francisco Campos}

\section{A. de Souza Costa}

Eurico G. Dutra

Henrique A. Guilhem

João de Mendonça Lima

Oswaldo Aranha

Fernando Costa

\section{Gustavo Capanema}

Waldemar Falcão

(D.O., seção I, 16/12/1939) pág. 28.649 .

\section{2 - DECRETO-LEI N. ${ }^{\circ} 2.039-$} DE 27 DE FEVEREIRO DE 1940

Transforma o Serviço de Publicidade do Departamento Administrativo do Serviço Público em Serviço de Documentação
O Presidente da República, usando da atribuição que the confere 0 art. 180 da Constituição, e atendendo ao que dispōe o art. $2 .^{\circ}$ do decreto-lei n. $^{\circ} 1.915$, de 27 de dezembro de 1939, decreta :

Art. $10^{\circ}$ O Serviço de Publicidade do Departamento Administrativo do Serviço Público, a que se refere o art. 11 do decreto-lei 579 , de 30 de julho de 1938, fica transformado em Serviço de Documentação.

Parágrafo único. No quadro permanente do mesmo Departamento, a função gratificada de chefe do Serviço de Publicidade passa a ser a de chefe do Serviço de Documentação.

Art. 2. ${ }^{\circ}$ Cumpre, principalmente, ao Serviço de Documentação:

a) coligir, ordenar, classificar, guardar, conservar e publicar os textos documentários, elementos estatísticos e dados discriminativos referentes às atividades do Departamento;

b) fornecer ao Departamento de Imprensa e Propaganda, mediante solicitação, os elementos de que este necessitar para 0 desempenho de suas atribuições, bem assim encaminhar ao mesmo o noticiário de suas atividades, cuja divulgação seja de interesse;

c) reunir dados para $o$ relatório anual do presidente do Departamento;

d) promover a divulgação de trabalhos de interesse da administração pública.

Art. 3. o presente decreto-lei entrará em vigor na data de sua publi- 
cação, revogadas as disposições em contrário.

Rio de Janeiro, 27 de fevereiro de $1940,119 .^{\circ}$ da Independência e $52 .^{\circ}$ da República.

\section{GETÚLIO VARGAS}

Francisco Campos

\section{3 - DECRETO-LEI N. ${ }^{\circ} 4.506$ -} DE 22 DE JULHO DE 1942

Cria o Serviço de Documentação (SD) do Departamento Administrativo do Serviço Público (DASP) e dá outras providências.

O Presidente da República, usando da atribuição que the confere 0 artigo 180 da Constituição, decreta:

Art. 1. ${ }^{\circ}$ Fica criado o Serviço de Documentação, (SD) do Departamento Administrativo do Serviço Público (DASP), diretamente subordinado ao Presidente do mesmo Departamento, compreendendo a Biblioteca, a Seção de Documentação e a Revista do Serviço Público, atualmente existente no DASP, e, ainda, uma Seção de Estatística Administrativa.

Art. 2. ${ }^{\circ}$ Fica criado, no Quadro Permanente "do DASP, o cargo, em comissão, de Diretor do Serviço de Documentação, padrão $\mathrm{N}$.

Art. 3. ${ }^{\circ}$ Para atender, no presente exercício, à despesa decorrente do disposto no artigo anterior, fica aberto, ao Departamento Administrativo do Serviço Público, o crédito suplementar na importância de 15:500\$0 (quinze contos e quinhentos mil réis) à Ver- ba 1 - Pessoal, Consignação I Pessoal Permanente, Subconsignação 01 - Pessoal Permanente (Anexo 3 - Decreto-lei n. ${ }^{\circ} 3.960$, de 19 de dezembro de 1941).

Art. $4 .^{\circ}$ Fica sem aplicação na Verba 1 - Pessoal, Consignação II - Pessoal Extranumerário, Subconsignação 04 - Contratados, do vigente Orçamento do Departamento Administrativo do Serviço Público (Anexo 3 - Decreto-lei n. ${ }^{\circ} 3.960$, de 19 de dezembro de 1941), a importância de 15:500\$0 (quinze contos e quinhentos mil reis).

Art. $5 .^{\circ} \mathrm{O}$ presente decreto-lei entrará em vigor a partir de $1 .^{\circ}$ de agosto de 1942 , revogadas as disposições em contrário.

Rio de Janeiro, 22 de julho de $1942,121 .^{\circ}$ da Independência e $54 .^{\circ}$ da República.

\section{GETÚLIO VARGAS}

\section{A. de Souza Costa}

- (D.O., Seção I, 24-7-1940, página 11.595).

\section{1 - PORTARIA N. ${ }^{\circ} 992-$ DE 3 DE OUTUBRO DE 1944}

O Presidente do Departamento Administrativo do Serviço Público, no uso da atribuição que the confere o art. $69, \mathrm{n} .{ }^{\circ}$ XVIII, do Regimento aprovado pelo Decreto n. ${ }^{\circ} 11.101$, de 11 de dezembro de 1942 :

Considerando que ao Serviço de Documentação do DASP compete a elaboração e a publicação de "Livros 
e pariódicos de interesse para a Administração Pública" (art. 48 do Regimento aprovado pelo Decreto $n .^{\circ}$ 11.101, de 11-12-42);

Considerando que a edição de uma revista especializada em questões de Direito Administrativo se impõe como fator indispensável à "sistematização dos fundamentos jurídicos da reforma administrativa brasileira", tarefa que incumbe aos órgãos do DASP, e especialmente ao seu Consultor Jurídico (art. 79 do Regimento citado);

Considerando as razões e o plano de edição expostos pelo Consultor Jurídico em ofício datado de $29-4-44$, já aprovados, resolve:

1. ${ }^{\circ}$ - Fica o Serviço de Documentação do DASP autorizado a editar a Seção II da Revista do Serviço Públi$\mathrm{co}$, intitulada "Revista de Direito Administrativo";

2. ${ }^{\circ}$ - A "Revista de Direito Administrativo" publicará, em fascículos trimestrais, trabalhos de natureza jurídica, relacionados com o serviço público, especialmente de Direito administrativo;

3. ${ }^{\circ}$ A "Revista de Direito Administrativo" terá direção técniça autô. noma; as despesas de material e de pessoal, de colaboração, permanente ou eventual, necessárias à sua edição, correndo por conta das Verbas do Serviço de Documentação;

\section{4. ${ }^{\circ}$ - O pessoal da "Revista do} Serviço Público" prestará o auxílio que for solicitado para a feitura da "Revista de Direito Administrativo;

$5 .^{\circ}$ - A direção da "Revista de Di- reito Administrativo" caberá ao Consultor Jurídico do DASP;

6. ${ }^{\circ}$ - O controle econômico e financeiro da edição da Revista de Direito Administrativo competirá ao Diretor do Serviço de Documentação.

Em 3 de outubro de 1944 - Luiz Simões Lopes. Publicado no Diário Oficial (Seção I) de 5-10-44, — pág. 17.224 .

\section{$2.2-$ CIRCULAR 124}

Em 27 de fevereiro de 1940

\section{Senhor Ministro}

Como é do conhecimento de Vossa Excelência, o decreto-lei $n .^{\circ} 1.870$, de 14 de dezembro de 1939, considerou a Revista do Serviço Público, editada por este Departamento, órgão de interesse da Administração.

Estabeleceu o mesmo decreto-lei que o custeio da Revista correrá à conta das dotações para isso consignadas no orçamento da União, sendo a renda, constante exclusivamente de assinaturas e da renda avulsa, recoIhida mensalmente ao Tesouro, como receita ordinária.

Atenta à finalidade dessa publicação, que é, não só a divulgação dos atos do Governo, como e principalmente a ativa propaganda dos meios de aperfeiçoar sob todos os aspectos, os serviços administrativos, é de maior interesse que a tiragem da Revista aumente constantemente, saindo do âmbito das repartições e dos gabinetes, na capital do País, para 
estender-se, tornando-se conhecida, quando não imprescindível, em todo o território nacional.

A Sua Excelência o Senhor Doutor Fernando Costa, Ministro de Estado da Agricultura. Nos mesmos termos aos demais Ministros de Estado.

Para alcançar esse objetivo, que é o deste Departamento, faz-se necessário o concurso de todos os ministérios, motivo pelo qual tenho a honra de dirigir-me a Vossa Excelência, solicitando as providências indispensáveis no sentido de, à conta de cada uma das diferentes verbas destinadas à aquisição de livros, jornais, revistas etc., ser tomado um certo número de assinaturas destinadas à remessa, que poderá ser feita pela própria Revista, se Vossa Excelência não determinar o contrário, às repartições e serviços nos Estados.

Assim, atendido o presente pedido, facilmente poderão ser distribuídos, por todo o Brasil, quatro a cinco mil exemplares da Revista, o que contribuirá poderosamente para divulgar os métodos de trabalho pelos quais ativamente se empenha o Estado Novo.

Aproveito a oportunidade para renovar a Vossa Excelência os protestos da minhă alta estima e mais distinta consideração. Presidente - Luiz Simões Lopes.

MINISTÉRIO DA FAZENDA - Gabinete do Ministro

\section{CIRCULAR N. ${ }^{\circ} 24$}

O Ministro de Estado dos Negócios da Fazenda, tendo em consideração que a "Revista do Serviço Público" insere em suas páginas matéria de grande interesse para os servidores públicos e de utilidade para a Administração em geral, já pelos problemas técnicos que ventila, já pela divulgação de assuntos gerais de Administração, resolve :

a) recomendar aos Senhores Chefes das repartições subordinadas a este Ministério a conveniência de tomarem assinatura da citada Revista, dentro das possibilidades da dotação orçamentária própria de sua repartição;

b) estender, particularmente, a recomendação aos servidores deste $\mathrm{Mi}$ nistério, dadas as vantagens que advirão para o serviço com o manuseio daquela publicação. Em 12 de juIho de 1944. Paulo Lyra - Respondendo pelo Expediente do Ministério da Fazenda.

Recomendação do Ministro da Fazenda, publicada em Diário Oficial de 14 de julho de 1944, página 12.418.

Observação: (Documento semeIhante foi expedido pelos demais Ministros ao Presidente Getúlio Vargas prestigiando a RSP).

DECRETO N. ${ }^{\circ}$ 66.222, DE 17 DE FEVEREIRO DE 1970.

Reorganiza o Departamento Administrativo do Pessoal Civil (DASP) e dá outras providências.

O Presidente da República, etc. . . 
Art. 10. O Centro de Documentação e Informática compõe-se de :

IV - Revista do Serviço Público

Art. 11. Compete ao DASP, através do Centro de Documentação e Informática :

2. Editar a Revista do Serviço Público, o Boletim "Diretrizes" e trabaIho sobre matéria técnica ou administrativa.

\section{- D. O. $18-2-71$ - pág. 1.231}

PORTARIA N. ${ }^{\circ} 131$, DE 2 DE JUNHO DE 1970

O Diretor-Geral do Departamento Administrativo do Pessoal Civil (DASP), no uso da atribuição que the confere o artigo 20 do Decreto número 66.222, de 17 de fevereiro de 1970 , resolve :

Art. $1^{\circ}$ Aprovar o Regimento do Departamento Administrativo do Pessoal Civil (DASP), na forma do anexo.

\section{R. Serv. públ., Brasília, 109 (2) abr./jun. 1974}

Art. 17. Compete ao Centro de Documentação e Informática ...... (CENDOC), através de suas unidades de trabalho:

5. Editar a "Revista do Serviço Público", com o propósito de divulgar matéria doutrinária, informativa, crítica e noticiosa, que contribua para maior difusão dos conhecimentos relativos à Administração Pública, notadamente à Administração de Pessoal.

(Publicada no D.O. de 4-6-70, página 4.143 ).

DECRETO N..$^{\circ} 71.922$, DE 15 DE MARÇO DE 1973

- Eleva a Revista do Serviço Público à categoria de "Unidade Estrutural do DASP (Art. 5. que alterou o Decreto n. ${ }^{\circ} 66.222$, de 1970).

DECRETO N. ${ }^{\circ} 71.923$, DE 19 DE MARÇO DE 1973

- Classifica o cargo de Diretor da RSP no Grupo DAS - Direção e Assessoramento Superior.

CONTRATO DASP/Editora Gráfica Alvorada Ltda., publicado no Diário Oficial de 24 de maio de 1973.

CONTRATO DASP/MINAS GRÁFICA EDITORA LTDA., assinado a 19 de fevereiro de 1974. 